\section{Simple and Low-Cost Thermal Treatments on Direct Resin Composites for Indirect Use}

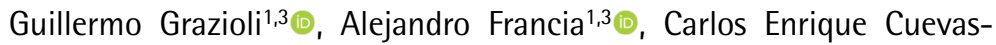

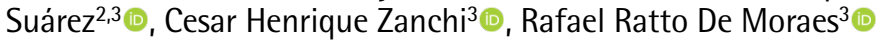

'Faculty of Dentistry, University of the Republic, Montevideo, Uruguay ${ }^{2}$ Academic Area of Dentistry, Autonomous University of Hidalgo State, Pachuca, México ${ }^{3}$ Graduate Program in Dentistry, UFPEL - Universidade Federal de Pelotas, Pelotas, RS, Brazil

Correspondence: Prof. Rafael Moraes, Rua Gonçalves Chaves 457, 96015-560, Pelotas, RS, Brasil. Tel: +55-53-3225-6741. e-mail: moraesrr@gmail.com

The aim of this study was to evaluate the influence of three low-cost additional thermal treatments, available in the dental office, on the mechanical, chemical and optical properties of a light-cured resin composite indicated for direct restorations but used as indirect restorative. The direct resin composite TPH3 (Dentsply) was light-polymerized using a light-emitting diode curing unit and submitted to three experimental additional thermal treatments: dry heat at $170^{\circ} \mathrm{C}$ for $5 \mathrm{~min}$, autoclave at $121^{\circ} \mathrm{C}$ for $6 \mathrm{~min}$, or microwave oven at $450 \mathrm{~W}$ for $3 \mathrm{~min}$. The resin composite without any thermal treatment was used as negative control group. An indirect resin composite (Vita CM LC, Vita Zahnfabrik) was tested as a reference. Flexural strength, elastic modulus, microhardness, degree of $C=C$ conversion, roughness before and after simulated toothbrush abrasion, translucency parameter and color difference $\left(\Delta \mathrm{E}_{00}\right)$ were evaluated. Data were analyzed at $\alpha=0.05$. The indirect resin composite presented lower $\mathrm{C}=\mathrm{C}$ conversion and mechanical performance. The flexural strength was significantly higher in the dry oven group compared with the control. The roughness was not different among groups before or after brushing, but the thermal treatments caused an increase in $\mathrm{C}=\mathrm{C}$ conversion, microhardness, and elastic modulus without affecting the translucency parameter or showing visible color alteration $\left(\Delta \mathrm{E}_{00}<1.8\right)$. These results suggest that the use of additional thermal methods of polymerization represents an economical and simple alternative to enhance the mechanical and chemical properties of direct resin composites when used as indirect restoratives.
Key Words: polymerization, mechanical properties, dental restoration.

\section{Introduction}

One of the major goals in the restorative dentistry is the development of low-cost procedures with high clinical success rates and durability, low complexity and predictable results. Inlay and onlay restorations can be performed using resin composite either by direct or indirect methods, and the selection of one or another will depend on the evaluation of costs, marginal fitting, clinical chair time, and mechanical properties, among other factors (1). Restorations with resin composite placed through a direct method usually require fewer clinical sessions and are less costly since they do not require laboratory steps. However, a direct technique might not be the most suitable treatment in some clinical situations, where the achievement of an optimal proximal anatomy, contact point, and marginal sealing is complex and not always successful (2). In addition, the chair time tends to be longer and the risk of contamination by moisture greater in direct restorations (3).

The indirect method involves the manufacture of a restoration outside the mouth using a gypsum or silicone mold obtained from an oral impression. This indirect technique allows to optimize the physical-mechanical and chemical properties of the polymeric materials by performing their polymerization under controlled conditions and without the generation of polymerization stresses (4). The composition of direct and indirect resin composite does not differ significantly, their main difference being restricted to the light-polymerization method $(5,6)$. Indirect resin composites are light-polymerized using strobe lights, sometimes under vacuum, associated with heat generation (5). This means that special equipment is necessary and that the costs are higher. These polymerization conditions are associated with an increase in the degree of $\mathrm{C}=\mathrm{C}$ conversion, which might result in improved physical and mechanical properties, color stability, and wear resistance $(6,7)$.

In the literature, the use of direct resin composite subjected to various additional thermal treatments as indirect restoratives has been proposed $(4,5)$. These thermal treatments are accomplished using conventional sterilization oven, autoclave, ceramic furnace, or microwave oven. These devices are usually present in a dental office and could offer advantages in terms costs for additional thermal treatment of direct composites as compared with the laboratory processing of indirect restoratives (4). However, these studies usually concentrate on mechanical properties of the resin composite without investigating their 
optical properties. Therefore, the aim of this study was to investigate the effect of thermal treatments of a direct resin composite (dry oven, autoclave, and microwave oven) on the flexural strength, elastic modulus, microhardness, degree of $\mathrm{C}=\mathrm{C}$ conversion, toothbrush abrasion, translucency, and color stability. An indirect resin composite was tested as a commercial reference. The study hypothesis was that the use of additional treatments would improve the mechanical properties without significantly affecting the optical characteristics of the resin composite.

\section{Material and Methods}

\section{Experimental Design}

In this in vitro study, a physical and chemical characterization of a light-cured resin composite indicated for direct restorations (TPH3; Dentsply, Konstanz, Germany, shade B2) was performed according to different polymerization protocols: light-activation only (negative control), light-activation followed by heating in dry oven, light-activation followed by heating in autoclave, and light-activation followed by heating in microwave oven. As a commercial reference, a resin composite indicated for indirect restorations (VitaVM LC; Vita Zahnfabrik, Bad $\dot{\delta}$ Sackingen, Germany, shade 2M1) was tested. The response variables were flexural strength $(n=10)$, elastic modulus $(n=10)$, degree of $C=C$ conversion $(n=5)$, microhardness $(n=5)$, and color stability $(n=8)$.

\section{Thermal Treatments}

In the negative control group, the resin composite was light-activated using a light-emitting diode curing unit (Optilight Max LED; Gnatus, Ribeirão Preto, SP, Brazil) with an irradiance of $950 \mathrm{~mW} / \mathrm{cm}^{2}$. The light intensity was constantly monitored using a radiometer (Bluephase ${ }^{\circledR}$ meter II, Ivoclar Vivadent, Schaan, Liechtenstein). The other groups tested were:

Indirect resin composite: Vita VM LC was processed following the manufacturer's instructions using a curing unit (UniXS; Heraeus Kulzer, Wehrheim, Germany), which uses high intensity stroboscopic lights. The specimens were let to cool down at room temperature.

Dry oven: the resin composite was light-activated and thermal treated in a pre-heated dry oven (Aesculap, Werke Tuttlingen, Germany) at $170^{\circ} \mathrm{C}$ for $5 \mathrm{~min}$, and the specimens were let to cool down at room temperature.

Autoclave: the resin composite was light-activated and thermal treated in an autoclave (model AVT-23L; Stermax, Curitiba, PR, Brazil) at $121{ }^{\circ} \mathrm{C}$ for $6 \mathrm{~min}$ at a $1.5 \mathrm{~kg} / \mathrm{cm}^{3}$ pressure, and the specimens were let to cool down at room temperature.

Microwave: the resin composite was light-activated and thermal treated in a microwave oven (Panavox, China) at
$450 \mathrm{~W}$ for $3 \mathrm{~min}$, and the specimens were let to cool down at room temperature.

\section{Flexural Strength and Elastic Modulus}

Ten bar-shaped specimens $(2 \times 2 \times 25 \mathrm{~mm})$ were prepared for each group by filling the uncured composite material into an acrylic mold placed on a glass slide covered by an acetate strip. Samples were light-irradiated on both sides by an overlapping technique according to the ISO 4049 standard (8). Each overlap was light-cured for $20 \mathrm{~s}$. After the polymerization, flashes and irregularities were removed with 400-grit SiC abrasive papers. The dimensions of the specimens were checked with an accuracy of 0.01 $\mathrm{mm}$ using a digital caliper. The specimens were stored in distilled water at $37^{\circ} \mathrm{C}$ for $24 \mathrm{~h}$. A 3-point bending test was performed using a MTS SANS CMT2000 universal test machine (Sans Testing Machine, Shen Zhen, China) at a crosshead speed of $0.75 \mathrm{~mm} / \mathrm{s}$ until fracture. Flexural strength $\left(\sigma_{f}\right)$ and elastic modulus $\left(\mathrm{E}_{f}\right)$ were determined using the following equations:

$$
\sigma_{f}=3 P l / 2 b h^{2} \quad E_{f}=3 P 1 l^{3} / 4 b h^{3} d
$$

where $P$ is the load at the time of fracture $(N), I$ is the distance between the supports $(20 \mathrm{~mm}), b$ is the width $(\mathrm{mm})$ and $\mathrm{h}$ is the height of the specimen $(\mathrm{mm}), \mathrm{P} 1$ is the maximum load on the linear portion (proportional limit) of the stress-deformation trace, and $d$ is the deflection of the specimen at load P1.

\section{Microhardness}

Five specimens retrieved from the 3-point bending test were embedded in PVC tubes with transparent self-curing acrylic resin, leaving the top surface of the specimens exposed. The exposed surfaces were sequentially wetpolished using a metallographic polisher (Aropol E; Arotec Colombiana SA, Bogota, Colombia) using 320,600, 1200, 1500, and 2000-grit SiC abrasive papers. Hardness readings was performed using a microindenter (FM700; Future-tech, Kawasaki, Japan) with a Knoop diamond using a $50 \mathrm{~g}$ load for a $15 \mathrm{~s}$ dwell time. Three indentations per specimens were performed and averaged. Data were recorded as Knoop hardness number $\left(\mathrm{kgf} / \mathrm{mm}^{2}\right)$.

\section{Degree of $C=C$ Conversion}

The degree of $\mathrm{C}=\mathrm{C}$ conversion was evaluated using a Fourier Tranform Infrared (FTIR) spectrometer (Frontier, Perkin Elmer) using the $\mathrm{KBr}$ technique. A FIIR spectrum of the uncured material was recorded and used as a reference (monomer). To record the FTIR spectrum of the material before polymerization, $15 \mathrm{mg}$ of resin composite was mixed with $150 \mathrm{mg}$ of $\mathrm{KBr}$, subsequently, with the use of 
a hydraulic press, a pellet about $0.5 \mathrm{~mm}$ in thickness was obtained. The pellet was placed in a standard sample holder inside the equipment. The FTIR spectra of the polymerized materials were obtained from five fractured specimens retrieved from the 3-point bending test. Each specimen was finely pulverized in an agate mortar. After the grounding process, a pellet was obtained as described and another FIR spectrum was obtained. In each of the spectra obtained, the absorption band height of the $\mathrm{C}=\mathrm{C}$ aliphatic bond at $1637 \mathrm{~cm}^{-1}$ was determined, and the absorption band of the $\mathrm{C}=\mathrm{C}$ aromatic bond at $1609 \mathrm{~cm}^{-1}$ was used as internal reference. The degree of $\mathrm{C}=\mathrm{C}$ conversion of the materials was calculated using the following equation:

$$
\text { Degree of } \begin{aligned}
C & =C \text { conversion }(\%) \\
& =100\left[1-\left(\frac{A_{1637}}{A_{1609}}\right) \text { polymer } /\left(\frac{A_{1637}}{A_{1609}}\right) \text { monomer }\right]
\end{aligned}
$$

where $A 1637$ is the maximum height of the band at $1637 \mathrm{~cm}^{-1}$ and $\mathrm{A} 1609$ is the maximum height of the band at $1609 \mathrm{~cm}^{-1}$.

\section{Surface Roughness and Simulated Toothbrush Abrasion}

The surface roughness of six disk-shaped specimens (diameter $6 \mathrm{~mm}$, thickness $1 \mathrm{~mm}$ ) for each group was evaluated with a surface profilometer (Surftest SJ-301; Mitutoyo, Tokyo, Japan) using a screening length of 1.25 $\mathrm{mm}$, a cut-off point of $0.25 \mathrm{~mm}$, and a measurement speed of $0.5 \mathrm{~mm} / \mathrm{s}$. Each specimen was evaluated three times at different locations near the center of the disk, and the mean roughness was recorded. Measurements were performed before and after a simulated toothbrush abrasion procedure. For the brushing simulation, soft-bristled toothbrushes (Sorriso; Colgate) were mounted on a brushing machine (MEV 3Y-XT; Odeme, Luzerna, SC, Brazil). A total of $15 \mathrm{k}$ brushing cycles was applied in a linear movement of $2 \mathrm{~cm}$, using a 1:3 mass ratio of dentifrice/water slurry (Colgate ${ }^{\circledR}$ Sensitive Pro-AlivioTM; Colgate-Palmolive, São Paulo, SP, Brazil).

\section{Optical Properties}

For each group, 8 cylindrical specimens $(2 \mathrm{~mm}$ in thickness, $6 \mathrm{~mm}$ in diameter) were prepared by filling the uncured composite material into a stainless-steel mold placed on a glass slide covered by an acetate strip. The specimens were irradiated on both sides for $20 \mathrm{~s}$. CIELAB color readings were measured using a spectrophotometer (SP60; X-Rite, Grand Rapids, MI, USA) in the reflectance mode. All specimens were measured over a white $\left(L^{*}=93.1\right.$, $\left.a^{*}=1.3, b^{*}=5.3\right)$ and a black background $\left(L^{*}=27.9, a^{*}=0\right.$, $b^{*}=0$ ). A first analysis was performed only for the direct composite resin; the evaluation was performed after each thermal treatment and compared with the values obtained from the negative control group (without thermal treatment) using the white background. The objective of this first analysis was to evaluate if the application additional treatments would induce color alteration. To analyze the color variation $\left(\Delta \mathrm{E}_{00}\right)$, the following equation according to CIEDE2000 method was used (9):

$$
\Delta E_{00}=\left[\left(\frac{\Delta L^{\prime}}{K_{L} S_{L}}\right)^{2}+\left(\frac{\Delta C^{\prime}}{K_{C} S_{C}}\right)^{2}+\left(\frac{\Delta H^{\prime}}{K_{H} S_{H}}\right)^{2}+R_{T}\left(\frac{\Delta C^{\prime}}{K_{C} S_{C}}\right)\left(\frac{\Delta H^{\prime}}{K_{H} S_{H}}\right)^{\frac{1}{2}}\right.
$$

where $\Delta \mathrm{L}^{\prime}, \Delta \mathrm{C}^{\prime}$ and $\Delta \mathrm{H}^{\prime}$ are the mathematical differences in lightness, chroma, and hue. The rotation term RT is a function that accounts for the interaction between chroma and hue differences in the blue region, improving the color difference equation performance. The $K_{L} S_{L}$, $\mathrm{K}_{\mathrm{C}} \mathrm{S}_{\mathrm{C}}$ and $\mathrm{K}_{\mathrm{H}} \mathrm{S}_{\mathrm{H}}$ are empirical terms used for weighting the metric differences to the CIEDE2000 differences for each coordinate. Parametric factors were set to $\mathrm{K}_{\mathrm{L}}=2, \mathrm{~K}_{\mathrm{H}}=1$ and $K_{C}=1$. A second color analysis was carried out before and after the immersion of the specimens of all groups in a coffee solution at $37{ }^{\circ} \mathrm{C}$ for $24 \mathrm{~h}$. The coffee solution was prepared using $1 \mathrm{~g}$ powder (Nescafé ${ }^{\circledR}$ Original; Nestlé Brasil, São Paulo, SP, Brazil) and $50 \mathrm{~mL}$ water. $A \Delta \mathrm{E}_{00}$ value of 1.8 was considered a threshold for visually detectable color change since it corresponds to $50 \%$ visual perceptibility under clinical conditions (10). The Translucency Parameter (TP) of each specimen was calculated before immersion in the coffee solution using the following formula (11):

$\mathrm{TP}=\left[\left(\mathrm{L}^{*} \mathrm{~W}-\mathrm{L}^{*} b\right)^{2}+\left(\mathrm{a}^{*} \mathrm{w}-\mathrm{a}^{*} \mathrm{~b}\right)^{2}+\left(\mathrm{b}^{*} \mathrm{w}-\mathrm{b}^{*} b\right)^{2}\right]^{1 / 2}$

where " $w$ " refers to the CIELAB values for each specimen measured over the white background and " $b$ " over the black background.

\section{Statistical Analysis}

Statistical analysis was performed using the IBM SPSS Statistics ${ }^{\circledR}$ version 23 program (Armonk, NY, USA). Normality and homogeneity were checked beforehand. Data for flexural strength, elastic modulus, microhardness, degree of $\mathrm{C}=\mathrm{C}$ conversion and color alteration were analyzed using a One-Way Analysis of Variance (ANOVA) and the Tukey's post-hoc test. Roughness data were analyzed using Repeated Measures ANOVA. For all analyzes, the level of significance was set at $\alpha=0.05$.

\section{Results}

Results for the mechanical properties and $\mathrm{C}=\mathrm{C}$ conversion are presented in Table 1 . The indirect resin composite showed significantly lower $\mathrm{C}=\mathrm{C}$ conversion, flexural strength, elastic modulus, and microhardness than all the other groups tested $(p<0.001)$. The flexural 
strength was significantly higher for the resin composite thermal treated in the dry oven compared with the control $(p<0.001)$. The flexural strength was not significantly different in the autoclave $(p=0.998)$ and microwave $(p=0.136)$ groups compared with the control. All additional thermal treatments yielded significant increases in elastic modulus $(p<0.001)$ and surface hardness $(p<0.001)$ compared with the untreated restorative. The increase in

Table 1. Means (standard deviations) for the material properties evaluated

\begin{tabular}{lcccc}
\hline Group & $\begin{array}{c}\text { Flexural } \\
\text { strength (MPa) }\end{array}$ & $\begin{array}{c}\text { Elastic modulus } \\
(\mathrm{GPa})\end{array}$ & $\begin{array}{c}\text { Knoop hardness } \\
\left(\mathrm{kgf} / \mathrm{mm}^{2}\right)\end{array}$ & $\begin{array}{c}\text { Degree of C=C } \\
\text { conversion (\%) }\end{array}$ \\
\hline $\begin{array}{l}\text { Indirect } \\
\text { composite }\end{array}$ & $66.5(10.9)^{\mathrm{c}}$ & $2.8(0.1)^{\mathrm{c}}$ & $27.9(2.9)^{\mathrm{d}}$ & $34.9(1.3)^{\mathrm{c}}$ \\
Control & $91.4(13.5)^{\mathrm{b}}$ & $6.8(0.6)^{\mathrm{b}}$ & $84.5(9.7)^{\mathrm{c}}$ & $55.1(1.3)^{\mathrm{b}}$ \\
Dry 0ven & $123.7(14.3)^{\mathrm{a}}$ & $9.4(0.7)^{\mathrm{a}}$ & $128.6(5.6)^{\mathrm{a}}$ & $65.9(2.0)^{\mathrm{a}}$ \\
Autoclave & $110.8(17.6)^{\mathrm{ab}}$ & $8.9(0.4)^{\mathrm{a}}$ & $110.3(4.9)^{\mathrm{b}}$ & $68.4(1.3)^{\mathrm{a}}$ \\
Microwave & $110.9(23.4)^{\mathrm{ab}}$ & $8.8(0.5)^{\mathrm{a}}$ & $121.0(3.6)^{\mathrm{ab}}$ & $66.4(1.7)^{\mathrm{a}}$ \\
\hline
\end{tabular}

Different letters in each column indicate statistically significant differences $(\mathrm{p}<0.05)$. hardness in the dry oven group was 52\%. In addition, the $\mathrm{C}=\mathrm{C}$ conversion was significantly higher in the groups submitted to thermal treatments compared with the nontreated composite $(p<0.001)$.

Figure 1 presents the results for surface roughness before and after the brushing cycles and for the optical properties for all groups. The surface roughness (Fig. $1 A)$ was similar in all groups either before $(p=0.345)$ or after brushing $(p=0.642)$. For all groups, the simulated toothbrush abrasion yielded significant increase in roughness $(p<0.05)$. In the optical analyses, no significant differences in $\Delta \mathrm{E}_{00}$ (Fig. 1B) or TP (Fig. 1C) were observed among the additional thermal treatments or when these groups were compared with the control $(p=0.641)$, with $\Delta \mathrm{E}_{00}$ values below 1.8. After the specimens were immersed in the coffee solution (Fig. 1D), all $\Delta \mathrm{E}_{00}$ values were above the perceptibility threshold and the indirect resin composite had significantly higher
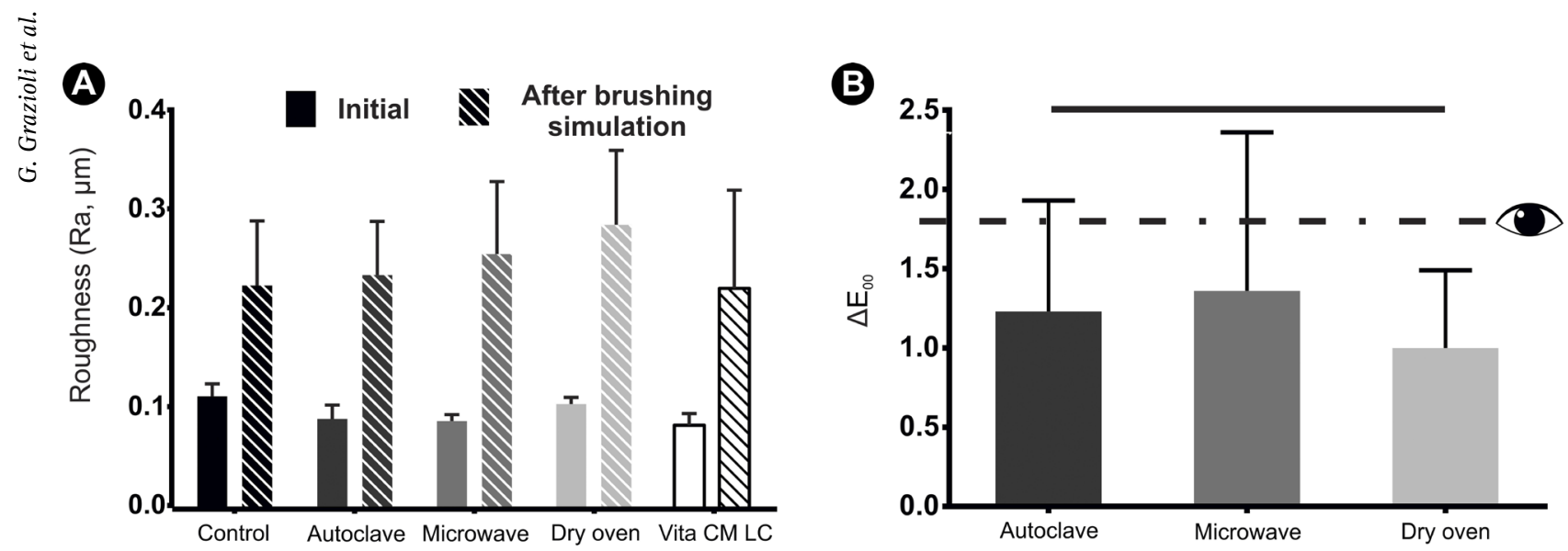

C

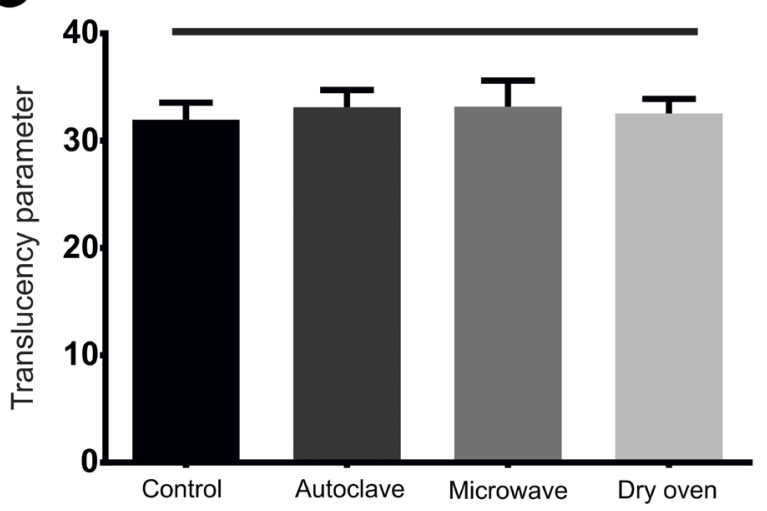

(D)

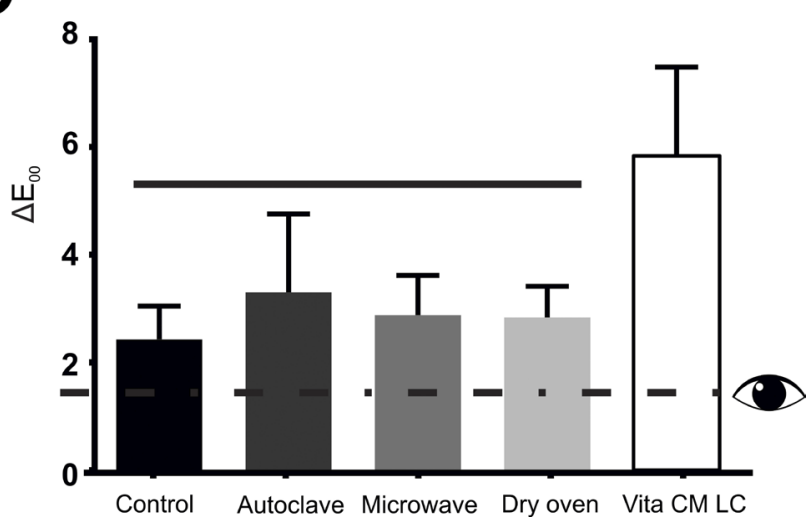

Figure 1. Means + standard deviations for surface roughness (A), color difference after the thermal treatments (B), translucency parameter (C) and color difference after immersion in coffee solution (D). Columns connected by horizontal lines are not statistically different. The value indicated by the dotted line at $\Delta \mathrm{E}_{00}=1.8$ corresponds to $50 \%$ visual perceptibility under clinical conditions and is used here as a reference for visually detectable color changes (9). 
color variation than all other groups $(p<0.001)$.

\section{Discussion}

The results of the present study provide evidence that the additional thermal treatments tested here applied to a direct resin composite may lead to significant gains in $\mathrm{C}=\mathrm{C}$ conversion and mechanical properties. In addition, no significant detrimental effect was observed in the surface roughness or optical properties of the restorative. Therefore, the hypothesis tested could not be rejected.

The indirect resin composite tested as a commercial reference showed the poorest mechanical performance in the study, which is corroborated by the results of previous investigations (12-14). Resin composites for indirect use were introduced in dentistry in the 1980's with the goal of providing a polymeric restorative with improved mechanical and optical properties (15). Indirect resin composites are polymerized under controlled and theoretically optimal conditions for monomer conversion and evolution of the mechanical properties thereof. These conditions often include a combination of heat, light and/or pressure (16). However, the $\mathrm{C}=\mathrm{C}$ conversion was significantly lower for the indirect resin composite, which may explain the poorer results observed in comparison with the direct composite. The lower $\mathrm{C}=\mathrm{C}$ conversion could be explained by the presence of a tetraacrylate monomer in the formulation of the indirect material. Acrylates are known for their high reactivity, and the presence of many functional groups may lead to polymer vitrification and the onset of polymerization autodeceleration to occur earlier, leading to and limiting further $\mathrm{C}=\mathrm{C}$ conversion (17). In addition, differences in the formulation of the indirect resin composite compared with the direct composite might also explain the present findings. Differences in the stiffness of the polymer network, inorganic filler loading and type or size of filler particles, for instance, may impact significantly the mechanical performance of polymeric composites (1820). However, the manufacturer of the indirect composite tested does not provide detailed information to allow a more in-depth analysis.

Previous studies have reported positive effects of different post-curing thermal treatments on the mechanical properties of resin composites indicated for direct restorations $(4,5,12,21-23)$. One study tested six additional post-curing methods and concluded that autoclave and microwave oven had the best results (12). In contrast, findings of the present study indicate that virtually all thermal treatments were able to yield positive effects for all properties evaluated. The positive effect is mainly related to heat increasing the mobility of unreacted monomers in the polymer network, leading to increased $\mathrm{C}=\mathrm{C}$ conversion and crosslink density of the network. In dimethacrylate- based composites, a limit of $\mathrm{C}=\mathrm{C}$ conversion is reached upon polymerization due to many factors, including reduced flow by increased viscosity and polymer vitrification (24). The size of the monomer molecules limits their capacity to form new bonds with more distant monomers. The application of different energy sources such as dry heat, wet heat, or microwave heat is able to increase the internal temperature of the material above its glass transition temperature $(T g)$, allowing an increase in the polymer chain mobility and favoring additional crosslinking and even some degree of polymerization stress relaxation (25).

In addition, the post-curing methods increase the consumption of the polymerization promoters, resulting in a lower residue of unreacted components and possibly reducing toxicity effects. It is known that the presence and oxidation of residual unreacted photoinitiators and reducing agents are responsible for the color change observed in dental composites over time. This means that the thermal treatments may also represent positive effects on the long-term color stability of the composite. In this study, color difference and translucency of the thermaltreated resin composite was evaluated in order to rule out a possible negative effect of the additional treatments, since it has been reported that color and translucency characteristics of dental composites are dependent on the curing characteristics (26). No significant differences in color and translucency were observed when the experimental treatments were compared with the control group. To the best of our knowledge, this is the first study in the literature to show this result.

A simulated toothbrush abrasion was used to observe whether the gains in mechanical properties would lead to gains in surface characteristics. However, the resin composite submitted to additional thermal treatments had similar surface roughness to the control group either before or after the brushing cycles. In addition, the untreated composite had the same color stability of the heat-treated composite groups after immersion in the coffee solution. These findings could be explained by the fact that surface roughness and color stability are affected not only by hardness and degree of $\mathrm{C}=\mathrm{C}$ conversion, but also by several other factors including filler size, percentage of surface area occupied by filler particles, filler/matrix interaction, stability of the silane coupling agent, and even polarity compatibility between the resin composite and colorants present in the coffee.

When analyzing the results altogether, it can be concluded that the additional thermal treatments tested here, performed with devices commonly available in any dental office, led to significant improvements in the resin composite mechanical properties. In addition, the additional treatments did not generate perceptible alterations in the 
optical properties of the material, allowing their use even in situations with high esthetic demand. These treatments also have the benefit of being economical and simple alternatives of easy application in the clinics.

\section{Resumo}

0 objetivo deste estudo foi avaliar a influência de três tratamentos térmicos adicionais de baixo custo, disponiveis no consultório dentário, nas propriedades mecânicas, quimicas e ópticas de uma resina composta fotoativada indicada para restaurações diretas porém usada como restaurador indireto. A resina composta direta TPH3 (Dentsply) foi fotoativada usando um diodo emissor de luz e submetida a três tratamentos térmicos adicionais experimentais: forno seco a $170^{\circ} \mathrm{C}$ por $5 \mathrm{~min}$, autoclave a $121{ }^{\circ} \mathrm{C}$ por $6 \mathrm{~min}$ ou forno de micro-ondas a $450 \mathrm{~W}$ por $3 \mathrm{~min}$. A resina composta sem qualquer tratamento térmico adicional foi usada como grupo controle negativo. Uma resina composta indireta (Vita CM LC, Vita Zahnfabrik) foi testada como referência comercial. Resistência à flexão, módulo de elasticidade, microdureza, grau de conversão de $\mathrm{C}=\mathrm{C}$, rugosidade antes e após abrasão por escovação simulada, parâmetro de translucidez e diferença de cor $\left(\Delta \mathrm{E}_{00}\right)$ foram avaliados. Os dados foram analisados considerando $\alpha=0.05$. A resina composta indireta apresentou menor conversão de $\mathrm{C}=\mathrm{C}$ e desempenho mecânico. A resistência à flexão foi significativamente mais alta no grupo forno seco comparado ao controle. A rugosidade não foi diferente entre os grupos antes ou após a escovação, porém os tratamentos térmicos adicionais causaram aumento na conversão de $\mathrm{C}=\mathrm{C}$, microdureza e módulo de elasticidade, sem afetar $\mathrm{o}$ parâmetro de translucidez ou mostrar alteração de cor visivel $\left(\Delta \mathrm{E}_{00}<1,8\right)$. Estes resultados sugerem que o uso de métodos térmicos adicionais de polimerização representam alternativa econômica e simples para aprimorar as propriedades mecânicas e químicas de resinas compostas diretas quando utilizadas como restauradores indiretos.

\section{Acknowledgements}

The authors acknowledge the generous support of Prof. Adj. Lab. Rodrigo Goinheix and Lab. Gonzalo Palmarin from the "Laboratorio Central de Protesis" of Faculty of Dentistry - University of the Republic at Montevideo. This study was financed in part by the Coordenação de Aperfeiçoamento de Pessoal de Nivel Superior (CAPES), Brazil (Finance Code 001).

\section{References}

1. da Veiga AMA, Cunha AC, Ferreira DMTP, da Silva Fidalgo TK, Chianca $T K$, Reis $K R$, et al. Longevity of direct and indirect resin composite restorations in permanent posterior teeth: A systematic review and meta-analysis. J Dent. 2016;54:1-12.

2. Loguercio $A D$, De Oliveira Bauer JR, Reis $A$, Grande RHM. In vitro microleakage of packable composites in Class II restorations. Quintessence Int 2004;35:29-34.

3. Demarco FF, Corrêa MB, Cenci MS, Moraes RR, Opdam NJM. Longevity of posterior composite restorations: Not only a matter of materials. Dent Mater 2012;28:87-101.

4. Almeida-Chetti VA, Macchi RL, Iglesias ME. Effect of post-curing treatment on mechanical properties of composite resins. Acta Odontológica Latinoam 2014;27:72-76.

5. Santana IL, Lodovici E, Matos JR, Medeiros IS, Miyazaki CL, RodriguesFilho LE. Effect of experimental heat treatment on mechanical properties of resin composites. Braz Dent J 2009;20:205-210.

6. Sideridou I, Tserki V, Papanastasiou G. Effect of chemical structure on degree of conversion in light-cured dimethacrylate-based dental resins. Biomaterials 2002;23:1819-1829.

7. Terry DA, Touati B. Clinical considerations for aesthetic laboratoryfabricated inlay/onlay restorations: a review. Pr Proced Aesthet Dent 2001;13:51-58.

8. International Organization for Standardization. ISO 4049:2009
Dentistry Polymer based restorative materials. 2009

9. International Commission on Illumination. Colorimetry. Commission Internationale de l'Eclairage; 2004. $72 \mathrm{p}$.

10. Paravina $R D$, Ghinea $R$, Herrera $L$, Bona $A D$, Igiel $C$, Linninger $M$, et al. Color difference thresholds in dentistry. J Esthet Restor Dent 2015;27:S1-S9.

11. Johnston WM, Ma T, Kienle BH. Translucency parameter of colorants for maxillofacial prostheses. Int J Prosthodont 1995;8:79-86.

12. Soares CJ, Pizi EC, Fonseca RB, Martins LR. Mechanical properties of light-cured composites polymerized with several additional postcuring methods. Oper Dent 2005;30:389-394.

13. Stawarczyk B, Egli R, Roos M, Özcan M, Hämmerle CHF. The impact of in vitro aging on the mechanical and optical properties of indirect veneering composite resins. J Prosthet Dent 2011;106:386-398.

14. Borba $M$, Della Bona $A$, Cecchetti $D$. Flexural strength and hardness of direct and indirect composites. Braz Oral Res 2009;23:5-10.

15. Nandini S. Indirect resin composites. J Conserv Dent. 2010;13:184

16. Hirata $M$, Koizumi $H$, Tanoue $N$, Ogino T, Murakami M, Matsumura $H$. Influence of laboratory light sources on the wear characteristics of indirect composites. Dent Mater J 2011;30:127-135.

17. Stansbury JW. Dimethacrylate network formation and polymer property evolution as determined by the selection of monomers and curing conditions. Dent Mater 2012;28:13-22.

18. Schwantz JK, Oliveira-Ogliari A, Meereis CT, Leal FB, Ogliari FA, Moraes RR. Characterization of Bis-Acryl Composite Resins for Provisional Restorations. Braz Dent J 2017;28:354-361.

19. Salgado VE, Cavalcante LM, Moraes RR, Davis HB, Ferracane JL, Schneider LF. Degradation of optical and surface properties of resinbased composites with distinct nanoparticle sizes but equivalent surface area. J Dent 2017;59:48-53.

20. Moraes RR, Gonçalves LS, Lancellotti AC, Consani S, Correr-Sobrinho L, Sinhoreti MA. Nanohybrid Resin Composites: Nanofiller Loaded Materials or Traditional Microhybrid Resins? Oper Dent 2009;34:551-7.

21. Bagis $\mathrm{YH}$, Rueggeberg FA. The effect of post-cure heating on residual, unreacted monomer in a commercial resin composite. Dent Mater 2000;16:244-247.

22. Gagliani M, Fadini L, Ritzmann JM. Depth of cure efficacy of highpower curing devices vs traditional halogen lamps. J Adhes Dent 2002;4:41-47.

23. Santana IL, Mendes Júnior JG, Corrêa CS, Gonçalves LM, Souza EM, Sousa RC de. Effects of heat treatment on the microhardness of direct composites at different depths of restoration. Rev Odonto Ciência 2012;27:36-40.

24. Ogliari FA, Ely C, Zanchi CH, Fortes CBB, Samuel SMW, Demarco FF, et al. Influence of chain extender length of aromatic dimethacrylates on polymer network development. Dent Mater 2008;24:165-71.

25. D'Alpino PHP, Silva MS, Vismara MVG, Di Hipólito V, Miranda González $\mathrm{AH}$, de Oliveira Graeff CF. The effect of polymerization mode on monomer conversion, free radical entrapment, and interaction with hydroxyapatite of commercial self-adhesive cements. J Mech Behav Biomed Mater 2015;46:83-92.

26. Paravina RD, Ontiveros JC, Powers JM. Curing-dependent changes in color and translucency parameter of composite bleach shades. J Esthet Restor Dent 2002;14:158-166. 